\title{
Relationship between Willingness to Communicate in English and Classroom Environment
}

\author{
Yin Kun*, Fatiha Senom, Chew Fong Peng \\ Department of Language and Literacy Education, University of Malaya, Malaysia
}

Received March 15, 2019; Revised July 15, 2020; Accepted July 29, 2020

\section{Cite This Paper in the following Citation Styles}

(a): [1] Yin Kun, Fatiha Senom, Chew Fong Peng, "Relationship between Willingness to Communicate in English and Classroom Environment," Universal Journal of Educational Research, Vol. 8, No. 9A, pp. 41 - 50, 2020. DOI: 10.13189/ujer.2020.082006.

(b): Yin Kun, Fatiha Senom, Chew Fong Peng (2020). Relationship between Willingness to Communicate in English and Classroom Environment. Universal Journal of Educational Research, 8(9A,), 41 - 50. DOI: 10.13189/ujer.2020.082006.

Copyright $\bigcirc 2020$ by authors, all rights reserved. Authors agree that this article remains permanently open access under the terms of the Creative Commons Attribution License 4.0 International License

\begin{abstract}
Under a hybrid theoretical perspective involving positive psychology (PosPsy) and ecological paradigm, this research attempts to explore the interrelationship between classroom environment and willingness to communicate (WTC) in English among EFL (English as a foreign language) learners in the normal universities in Shandong province, China. A survey method is used engaging a questionnaire comprised of demographic information and items on classroom environment and L2 WTC. The statistical analysis was conducted based on 128 returned questionnaires. The findings confirmed that the EFL students in Shandong normal universities perceived themselves as having a high level of L2 WTC and classroom environment. What's more, a statistically significant positive relationship that is moderately strong between L2 WTC and classroom environment was found. Moreover, the multiple regression analysis identified that teacher support is the classroom environment dimension that is a statistically significant predictor of L2 WTC. The fitness indexes of the proposed structural model achieved the fitness required for Ratio Chisq/df (Chi-square/ Degrees of Freedom), CFI (Comparative Fit Index), and RMSEA (Root Mean Square of Error Approximation) at an acceptable level. Hence, the proposed structural model was established for this research.
\end{abstract}

Keywords Willingness to Communicate in English, Classroom Environment, Teaching English as a Foreign Language, Education, China

\section{Introduction}

\subsection{Background of WTC in English}

Teaching English as a foreign/second language (TEFL/TESL) has embraced numerous modifications and adjustments in the course of the last five decades. In prior times, English language teaching stressed the dominance of etymological structure, while more lately, it has underscored the language students' communicative competence and the actual language use in communication (Cetinkaya, 2005). Communicative language teaching given more weight to the pragmatic language use in communicative interaction in the actual process of second/ foreign language acquisition.

In highlighting the communicative uses of a foreign or second language, researchers like MacIntyre and Charos (1996) asserted that one must talk to learn and the language learners were highly suggested to develop proficiency through using the language. In other words, L2 learners are not able to become proficient if not communicatively use the language (Khajavy, Ghonsooly, Hosseini Fatemi, \& Choi, 2016).

Moreover, consistent with the current developments toward a colloquial method to foreign language instruction, the great significance of creating language in language utilization and communicative interaction has been supported and accentuated in well-renowned second language acquisition (SLA) theories. For instance, comprehensible output supposition (Swain \& Lapkin, 1995) and the interaction proposition (Long, 1996). 
Despite this, when language learners have the chance to use a foreign language, the disparity in talking the foreign language is found. Some students pursue every possible opportunity to say the second language (L2) inside the classroom, conversely, others keep silence.

WTC in L2 context is termed as an eagerness to engage in conversation at a special time with one or more specific persons, using an FL or L2 based on the study of MacIntyre, Dörnyei, Clément, and Noels (1998). As an individual difference (ID) factor, WTC in English in the foreign or second language rated to boost L2 acquisition. It explicates the disparities in students' intention to communicate using an $\mathrm{L} 2$ and has been widely examined in recent years by numerous scholars (Cao, 2014; Khajavy, MacIntyre, \& Barabadi, 2018; P. D. MacIntyre, 2007; Peng, 2019; Yu, 2015). In the context of pedagogy, the research into L2 WTC is of great importance based on it enables to interpret learners' promoting communication engagement and communicative psychology in the classroom. As was pointed out by MacIntyre et al. (1998), the preparing of WTC ought to be the fundamental objective of language instruction.

In China, the WTC in English also has been attached high importance by educational policy-makers. As noted by the Ministry of Education of China, to foster communicative competence and empower Chinese students to communicate in English in high-efficiency in terms of working, social communication, and learning is also regarded as one of the crucial targets for TEFL in China (College English Curriculum Requirements, 2007).

\subsection{Problem Statement}

Firstly, despite this, the L2 WTC level of Chinese students is still not high enough and little progress has been made in the enhancement of their L2 WTC (Wei, Gao, \& Wang, 2019; You \& Dörnyei, 2014). In China, English language course is one of the primary compulsory subjects for almost every Chinese student scoping from primary schools to the first two years in the university no matter what majors they learn (You \& Dörnyei, 2014). But Chinese TEFL teachers' series of pedagogical efforts are not always exchanged for the correspondingly expected students' active engagement in oral communication in the English classroom. To name a few, as TEFL in China is highly exam-oriented without exams for speaking skills, it is not infrequent for students to suspect the worth of "talking" in class for succeeding the College English Test (CET). TEFL learners usually unresponsively act in oral interaction in the English class. Such silence and non-engagement disappoint many TEFL practitioner and are not in line with the reform for English courses (Liu, 2002; Yu, 2001).

Many researchers have performed to investigate L2 WTC in conjunction with diverse of ID variables from perspectives of cognition, demographic information, linguistics, and communication. To illustrate, international posture, self-confidence, attitudes, motivation, personality, foreign language anxiety, learning aptitude, and language strategies (Ghonsooly, Khajavy, \& Asadpour, 2012; Joe, Hiver, \& Al-Hoorie, 2017; MacIntyre et al., 1998; Peng, 2019).

Most of the above studies explored L2 WTC in the settings of English as a second language (ESL) (Clément, Baker, \& MacIntyre, 2003; MacIntyre \& Charos, 1996). However, the essential role of classroom contextual variables is much less explored in L2 WTC research, in particular, in the context of EFL. The EFL context was of particular importance because compared with ESL settings, in the context of EFL, the English language classroom is the primary platform where EFL students can communicate and practice the English language (Oxford \& Shearin, 1994).

As mentioned above, to date, few studies have examined the role of the classroom environment into L2 WTC research in EFL setting

(Khajavy et al., 2016; Peng, 2019), and even if explored, very few of them have illuminated by Positive Psychology (PosPsy) perspective, let alone enlightened by both ecological paradigm and PosPsy concurrently.

Thereby, to account for the complexity of the role of foreign language classroom into WTC, and for the goal of reaching a better picture of L2 WTC, the present research targets on investigating L2 WTC with a focus on their language classroom setting among Chinese EFL students in normal universities in the province of Shandong, China.

\subsection{Research Objectives}

This research was designed to investigate EFL learners' assessment of their level of WTC in English and classroom environment in normal universities in Shandong Province, China. The research objectives are as below:

1. To assess the level of WTC in English (endogenous variable) in normal universities in Shandong Province, China.

2. To assess the level of classroom environment (exogenous variable) in normal universities in the province of Shandong, China.

3. To analyze the interrelationship between WTC in English and classroom environment in normal universities in Shandong Province, China.

4. To examine which dimensions of the classroom environment are the significant predictors of WTC in English in normal universities in Shandong Province, China.

5. To measure whether the proposed structural model engaging WTC in English and classroom environment fits with the data collected among EFL students from normal universities in Shandong Province, China. 


\subsection{Conceptual Framework}

This study attempts to investigate WTC in English (two dimensions: WTC in form-focused activities, WTC in meaning-focused activities) as the endogenous variable in relation to classroom environment (three dimensions: Students cohesiveness, Teacher support, Tasks orientation) as the exogenous variable. The theoretical framework for the present study was informed both by the ecological perspective on classroom dynamics (Bronfenbrenner, 1979) and positive psychology (Seligman \& Csikszentmihalyi, 2000) concurrently.

Firstly, the ecological perspective of human development underscores that the classroom environment places a strongly significant role in students' educational success apart from affective and cognitive factors. This was further buttressed by Leather and Dam (2003) who contended that students' cognitive behaviours were intersected with their social and physical surrounding. And the learning context is the ecological perspective theory's focus. Enlightened by Bronfenbrenner's (1979) ecological paradigm, the language classroom is viewed as a miniature social setting in which the students and teacher interact and treat with each other as social members using negotiation, communication, and compromise, instead of just a common learning place.

Hence, as employed to the present study, this theory asserts that if the EFL learners could obtain strong support and help from both teachers and peers, and realize the significance of learning tasks, they would be motivated and facilitated to have a high willingness to involve into classroom communication using $\mathrm{L} 2$.

Secondly, consistent with the positive turn introducing from positive psychology into SLA domain (Dewaele \& $\mathrm{Li}, 2020$; Lake, 2013), this research also tried to investigate the role of classroom environment under the theoretical perspective of PosPsy. Contrast with traditional psychology always paying attention to deficiency or diseases, PosPsy gives more weight to positive traits that empower people's self-actualization, satisfaction and success (Dewaele \& Li, 2020; Maslow, 1954). According to Seligman and Csikszentmihalyi (2000) and (Li \& Jiang, 2017), PosPsy owns "three pillars" (i.e. positive traits in individual layer, positive experiences in the subjective layer, and as well as positive institutions in the collective layer), and classroom environment is one the typical positive institutions featured with great communication characteristics and concurrently constructed by multiple or mutual communicators.

Thus, in this study, the conceptual framework drew on a hybrid theoretical perspective including both PosPsy and ecological paradigm simultaneously. The conceptual framework of the present research is shown in Figure 1.

\begin{tabular}{|l|c|}
\hline $\begin{array}{c}\text { EXOGENEOUS VARIABLE } \\
\text { Classroom Environment } \\
\text { (Fraser, 1998; Moos, 1979; Peng, 2010) } \\
\text { Three dimensions: }\end{array}$ & $\begin{array}{c}\text { ENDOGENEOUS VARIABLE } \\
\text { Willingness to Communicate in English }\end{array}$ \\
$\begin{array}{l}\text { 1. Students cohesiveness } \\
\text { 2. Teacher support } \\
\text { 3. Tasks orientation }\end{array}$ & $\begin{array}{c}\text { Two dimensions: } \\
\text { 1. Willingness to communicate in } \\
\end{array}$ \\
& form-focused activities \\
& 2. Willingness to communicate in \\
meaning-focused activities
\end{tabular}

Figure 1. Conceptual framework of this study 
In the present framework, the endogenous variable, WTC in English comprised two dimensions according to Peng and Woodrow's model (2010). Each of these two dimensions is operationally conceptualized as below:

1. "WTC in form-focused activities" refers to WTC when EFL learners are engaging in activities in which specific linguistic traits (to name a few, vocabulary, grammar, and pronunciation) are implicated. For example, asking the teacher the pronunciation of a word.

2. "WTC in meaning-focused activities" correlates WTC when EFL learners are participating in activities where message-exchanging is accentuated. For example, giving a speech for introducing his or her hometown in front of peers in class.

The exogenous variable, classroom environment entails three dimensions based on Dorman (2003) and Peng and Woodrow's studies (2010). Each of these three dimensions is operationally termed as below:

1. "Students cohesiveness" correlates how students support, understand, and help with peers (Dorman, 2003).

2. "Teacher support" captures how students perceive the trust, friendliness, interest and help to get from teachers (Dorman, 2003).

3. "Tasks orientation" means how students comprehend the worthiness of carrying out tasks and the meaning of the learning tasks (Dorman, 2003).

\section{Literature Review}

In recent research into WTC has revealed that situated and micro-level contextual factors affect language learning and instruction in the FL classroom (Pawlak, Mystkowska-Wiertelak, \& Bielak, 2016). Both qualitative (Cao, 2011, 2014; Peng, 2012) and quantitative studies (Khajavy et al., 2018; Peng, 2019) have used an ecological approach into L2 WTC in English.

In the quantitative research, classroom environment was termed as student cohesiveness, task orientation, and teacher support and found to directly facilitate students' L2 WTC in those researches.

For example, Peng and Woodrow (2010) integrated classroom environment into a posited model involving L2 WTC in English and three other ID variables (i.e. motivation, learner beliefs, and communication confidence) applying structural equation modelling (SEM) approach among 579 tertiary students in the context of China. Classroom environment was reported to both directly impact WTC (i.e., .18; $\mathrm{f}^{2}=.03$, small effect size; $\mathrm{R}^{2}=.03$ ), while indirectly impact WTC via the other three IDs variables including confidence, motivation, and learner beliefs (i.e., $.19 \times .69+.29 \times .38 \times .69+.33 \times .42$ $\times .69 ; \mathrm{f}^{2}=.10$, small ES; $\mathrm{R}^{2}=.09$ ). Concerning the operationalization of classroom environment, their study selected 13 items within the "What Is Happening In This Class” (WIHIC) (Fraser, Fisher, \& McRobbie, 1996), and piloted among 330 high school students using an exploratory factor analyses (EFA). In the main study of Peng and Woodrow's research, applying confirmatory factor analyses (CFA) the instrumentation for classroom environment was validated as a three-factor construct, that is, student cohesiveness, task orientation, and teacher support. Finally, classroom environment was contended to be a significant predictor of WTC in English, which indicates that an appealing environment can empower WTC. But the small effect size for the relations between classroom environment and WTC calls for additional discussion.

In line with Peng and Woodrow (2010), Khajavy et al. (2016) also proclaimed that classroom environment was an antecedent of WTC in English inside the classroom with 243 university students who were English majors from Iran using SEM. The minor difference between the two studies mentioned above is that in the latter study, the effect size is in medium instead of small. And the authors further concluded that in Iranian EFL context classroom environment plays a central role in L2 WTC.

Next, another research conducted by Khajavy et al. (2018) explored the relationships between WTC and classroom environment with 1528 Iranian students selected from 65 different classes in secondary schools. After applying a doubly latent multilevel approach, the researchers showed that a positive classroom environment pertinent to stimulating WTC.

The above quantitative finding is along with the qualitative research evidence achieved in Cao's (2011, 2014) and Peng's (2012) study arguing the significance of classroom contextual factors (i.e. interlocutors, task types, topic, class interactional pattern, and the teacher) exerted on WTC.

Grounded on the literature reviewed, quantitative and qualitative studies described a significant relationship between WTC inside the classroom and classroom environment or climate (Cao, 2011, 2014; Khajavy et al., 2018; Peng, 2012, 2019; Peng \& Woodrow, 2010). However, not many empirical researchers explored this relationship under the theoretical perspective of PosPsy but informed only by the ecological perspective.

Consistent with the "positive turn" for psychology, there are advocations toward introducing Positive Psychology, in particular, the positive institution into Second Language Acquisition (SLA). To name a few, MacIntyre and Mercer (2014) stated that those models towards communication and learning process are unfinished without clear attention to the various positive institutions and settings of learning. As one of three positive pillars of PosPsy, as in terms of collective layer, positive institutions, such as classroom environment has been given critically insufficient research attention to in research into SLA (Li \& Jiang, 2017). Thus, there is a 
pressing need to consider the positive institutions, in particular, classroom environment into L2 WTC research to achieve a richer comprehension of WTC in English inside the classroom.

At length, through the aforementioned literature, in this investigation, drawing both from an ecological perspective and positive psychological perspective, we supposed that classroom environment would impact WTC in English. Specifically, we attempt to explore the relationship between classroom environment and L2 WTC in English in normal universities in Shandong province of China by both PosPsy and ecology approach.

\section{Methodology}

\subsection{Research Design}

This research was designed to determine the interrelationship between L2 WTC in English as the endogenous variable with classroom environment as the exogenous variable. Accordingly, a quantitative research approach was utilized to set a path between variables (Fraenkel, Wallen, \& Hyun, 2011) or elucidate how one variable predicts another (Creswell \& Guetterman, 2019). Employing a survey approach, numerical data were gathered through the administration of a series of questionnaires adopted. The data collection instrument was a self-administered and cross-sectional questionnaire.

\subsection{Settings and Participants}

A total of 128 Chinese EFL undergraduates (Male $=51$, $39.8 \%$; Female $=77,60.2 \%$ ) selected from one normal university in a city in the middle east of Shandong Province of China were recruited in this survey (According to Tabachnick and Fidell (2019), SEM could be analyzed using 60 observations, though larger sample size is better). All participants represented various non-English majors (e.g., Radio and Television, Finance, and Cultural Industry Management) and were prepared to become teachers after graduation. The mean age of the participants was 18.88 years ( $\mathrm{SD}=0.78$ ), ranging from 17 to 21 . All the selected students were freshmen or sophomores. Fifty-five percent of the students $(n=71)$ were freshmen, $44.5 \%$ (n = 57) sophomores. Among them, most of them $(96.1 \%, \mathrm{n}=$ 123) reported having no overseas experience in any English-speaking countries or areas. In the sample, 63.3\% of the students ( $\mathrm{n}=81$ ) had been learning English for ten to twelve years, $36.7 \%(n=47)$ for six to nine years. We selected non-English major sophomores and freshmen because undergraduates had and only had the same compulsory course named College English in the first two years of their college studying life in China. And English-majors shared different English proficiency and learning environment with them.

\subsection{Instrument}

A set of questionnaires were adopted to acquire the numerical data needed for this research. The instrument consisted of participant demographic variables, L2 WTC in English, and classroom environment. Student demographic variables are age, gender, grade, major, hometown, overseas experience in English-speaking countries or areas, and year group for English learning,

WTC in English was assessed as per Peng and Woodrow's study (2010). This scale is comprised of 10 items underlying two dimensions which are: (i) WTC in form-focused activities; (ii) WTC in meaning-focused activities. This scale was initially adapted from Weaver's (2005) instrument of WTC in speaking setting, assessing the degree to which the respondents are inclined to communicate in some specific classroom situations. The 10 items were assessed on a standard 6-point Likert scale, covering from 6 (definitely willing) to 1 (definitely not willing). High points showed a high level of WTC.

The scale of classroom environment with 13 items was also adopted from Peng and Woodrow (2010), consisting of three dimensions: (i) Students cohesiveness; (ii) Teacher support; (iii) Tasks orientation. This scale was originally adapted from studies of Zhang and Oetzel (2006), Fraser et al. (1996), Fraser, Treagust, and Dennis (1986) and Clément, Dörnyei, and Noels (1994). It gauges the frequency with which the respondents feel their classroom environment as the way it is displayed in the statements. This scale was also rated on a 6-point Likert scale, anchoring from 6 "always" to 1 "never". Respondents who scored high showed the high positive perception of classroom environment.

This adopted instrument was pilot examined on 59 normal undergraduates in Jinan city, China. Data obtained were analyzed for internal consistency applying the Statistical Packages for the Social Sciences (SPSS) version 25. By the Cronbach's alpha value method, the Cronbach alpha coefficient for each dimension of WTC in English was obtained as .863 and .899, and dimensions underlying classroom environment was in the scope of $.860-.874$. These demonstrated that this instrument achieved reliability at an acceptable level ( $\alpha>$ >65) (Chua, 2013).

In the main study, prior to the model fitness test, the convergent and discriminant validity were achieved (all factor loadings of each item of WTC and CE (classroom environment) were between .586 and .964; CFI of each dimensions were $>.90$, RMSEA $<.08, \mathrm{CMIN} / \mathrm{DF}<5.0$; all the correlational coefficients for each item were in the range of .37- .80). And factor analysis value of each indicator, AVE, CR, Cronbach's alpha values were also established at corresponding acceptable levels.

\subsection{Analysis of Data}

Numerical data collected were quantitatively analyzed applying SPSS and Analysis of Moment Structures 
(AMOS) version 23.0. Both inferential and descriptive statistics were employed using SPSS to address the data to tackle the research questions proposed. To tackle the first two research questions, the descriptive statistical method including mean and standard deviation was employed. The composite mean for each of the dimension was combined into three groups with an equal interval in which 4.01 to 6.00 is interpreted as high; 2.01 to 4.00 is represented as a medium; and 0.00 to 2.00 as low. For inferential statistical method, the Pearson product-moment correlation test was carried out to validate the relations between classroom environment and WTC in English, while the multiple regression analysis was performed to evaluate which dimensions underlying classroom environment contribute to the changes in WTC in English. Finally, using AMOS, the SEM technique was conducted to identify if the data gathered fit with the hypothesized model integrated with classroom environment and WTC in English in Shandong normal universities.

\section{Findings}

In this section, the results of this study as per each research question were presented.

\section{Research Question 1:}

What are the levels of WTC in English in normal universities in Shandong, China?

Descriptive statistical methods were applied to analyze the numerical data gathered from 128 students in normal universities in Shandong, China. The results yielded through an analysis were reported in Table 1.

Table 1. Mean, Standard Deviation and the Level of WTC in English $(\mathrm{N}=128)$

\begin{tabular}{|c|c|c|c|}
\hline Dimension & Mean & $\begin{array}{l}\text { Standard } \\
\text { Deviation }\end{array}$ & Level \\
\hline $\begin{array}{l}\text { 1) WTC in meaning-focused } \\
\text { activities }\end{array}$ & 3.95 & 1.07 & Medium \\
\hline $\begin{array}{l}\text { 2) WTC in form-focused } \\
\text { activities }\end{array}$ & 4.40 & 1.20 & High \\
\hline Overall & 4.13 & 1.01 & High \\
\hline
\end{tabular}

Note: WTC $=$ Willingness to communicate in English

As shown in Table 1, the global mean for WTC in English was 4.13. This could be explained as a high level of WTC in English for students in normal universities in Shandong province of China. Concerning each dimension underlying WTC in English, WTC in meaning-focused activities showed a medium level of mean, while the other dimension, namely WTC in form-focused activities demonstrated a high level of mean.

\section{Research Question 2:}

What are the levels of classroom environment in normal universities in Shandong province of China?

The descriptive analysis results for the level of classroom environment were shown in Table 2.

Table 2. Mean, Standard Deviation and the Level of Classroom Environment ( $\mathrm{N}=128)$

\begin{tabular}{lccc}
\hline \multicolumn{1}{c}{ Dimension } & Mean & $\begin{array}{c}\text { Standard } \\
\text { Deviation }\end{array}$ & Level \\
\hline 1) Teacher support & 4.93 & 0.90 & High \\
\hline 2) Students cohesiveness & 4.83 & 0.94 & High \\
\hline 3) Tasks orientation & 4.67 & 0.99 & High \\
\hline Overall & 4.80 & 0.86 & High \\
\hline
\end{tabular}

According to Table 2, the overall mean for classroom environment was 4.80 , which could be accounted for a high level of classroom environment in normal universities in Shandong Province of China. Pertinent to each dimension of classroom environment, the analysis results for each dimension of classroom environment indicated that two out of the three classroom environment dimensions take a higher mean than the overall mean. These dimensions are teacher support and students cohesiveness. While the other dimension, tasks orientation indicated lower mean than the overall mean of classroom environment. Nevertheless, all the three dimensions underlying classroom environment have means that are explained as a high level. These denoted that the participants reported themselves as perceiving high level for all the three classroom environment dimensions in normal universities in Shandong province of China.

\section{Research Question 3:}

Is there a significant relationship between WTC in English and classroom environment in normal universities in Shandong province, China?

The Pearson product-moment correlation test was carried out to evaluate the relationship between classroom environment and WTC in English. The analysis results were shown in the bellowing Table 3.

Table 3. Pearson Product-Moment Correlation Analysis between WTC in English and Classroom Environment $(\mathrm{N}=128)$

\begin{tabular}{ccc}
\hline \multicolumn{2}{c}{ Variable } & $\begin{array}{c}\text { Willingness to } \\
\text { communicate in } \\
\text { English }\end{array}$ \\
\hline \multirow{2}{*}{$\begin{array}{c}\text { Classroom } \\
\text { Environment }\end{array}$} & $\begin{array}{c}\text { Pearson } \\
\text { Correlation }\end{array}$ & $.49^{* *}$ \\
\cline { 2 - 3 } & Sig. (2-tailed) & .00 \\
\cline { 2 - 3 } & $\mathrm{N}$ & 128 \\
\hline
\end{tabular}

Note: $* *$. Correlation is significant at the level of 0.01 (2-tailed).

Table 3 presented that for the research sample of the present study $(\mathrm{n}=128)$, there was a statistically significant positive correlation which was moderately strong $(\gamma=.49, \rho<.01)$ between WTC in English and classroom environment. 
Table 4. Multiple Regression (Stepwise) on classroom environment to WTC in English (N = 128)

\begin{tabular}{cccccccc}
\hline Variable & $\begin{array}{c}\text { (Unstad.) } \\
\mathrm{B}\end{array}$ & $\begin{array}{c}\text { (Stand.) } \\
\mathrm{B}\end{array}$ & $t$ & $\mathrm{Sig}$ & $\mathrm{R}^{2}$ & $\begin{array}{c}\text { Contribution } \\
(\%)\end{array}$ \\
\hline Teacher support & .51 & .50 & 6.48 & .000 & .244 & 24.4 \\
\hline Constant & 1.74 & & 4.62 & .000 & &
\end{tabular}

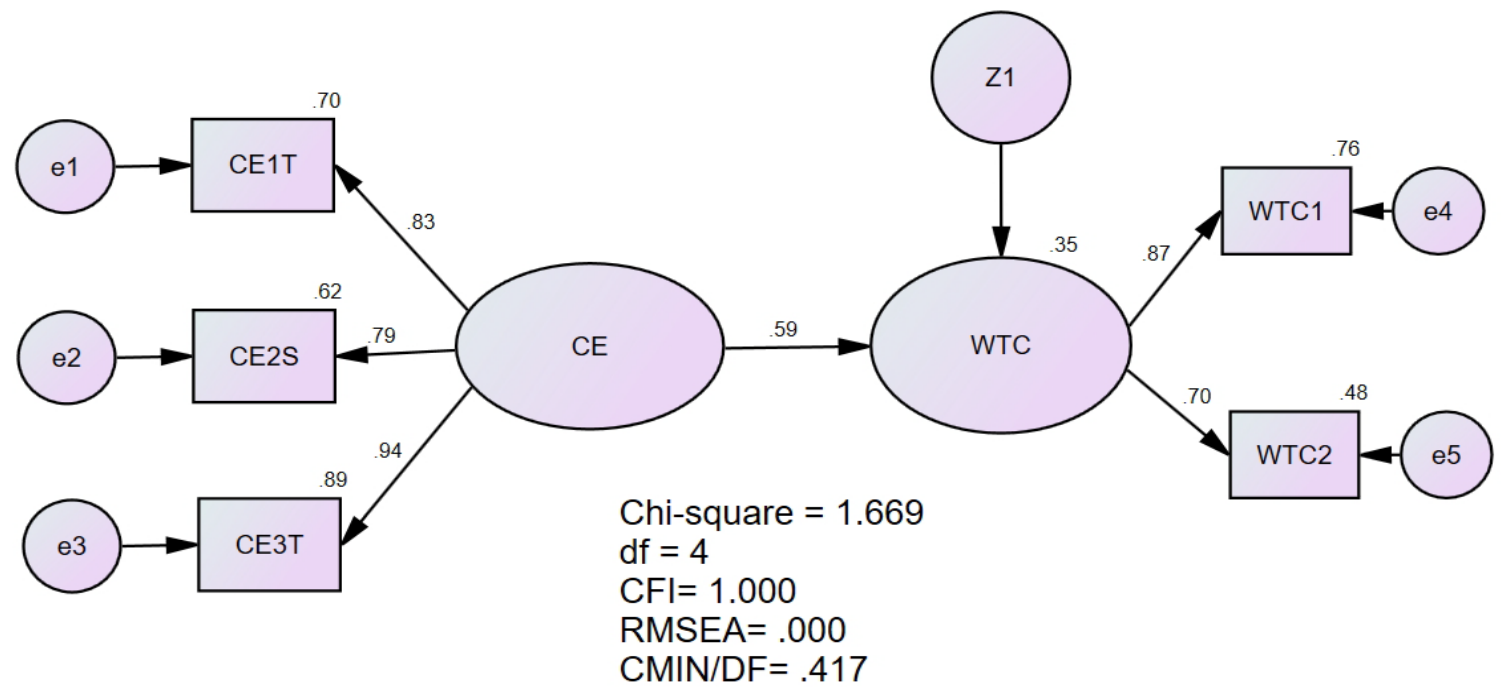

Note: $\mathrm{CE}=$ Classroom Environment; WTC=Willingness to Communicate in English

Figure 2. The Proposed Structural Model

\section{Research Question 4:}

Which dimensions of the classroom environment are the significant predictors of WTC in English in normal universities in Shandong Province, China?

The outputs of inferential statistics through the multiple regression analysis yielded were presented in following Table 4.

The outputs of multiple regression analysis presented in Table 4 denoted that the hypothesized model comprised one out of the three predictors. The only predictor was Teacher support $(\beta=.50, \rho=.000)$. Teacher support dimension underlying classroom environment was reported to account for $24.4 \%$ of the variance in WTC in English $\left(\mathrm{R}^{2}=.244\right)$. Informed by the benchmark range of effect sizes studied by Cohen's (1988), this model indicated a medium effect size on L2 WTC in English.

The dominant predictor for WTC in English is teacher support dimension of classroom environment $(\beta=.50, t=$ 6.48 and $\rho=.000$ ). The t-test output was significant at the significant level $(\rho<.05)$ with the $R^{2}=.244$, which illustrated that teacher support dimension contributes $24.4 \%$ of the variance in WTC in English. Grounded on the standardized beta value, when the teacher support dimension of the classroom environment increased by 1 unit of standard deviation, WTC in English would increase by .50 unit of standard deviation.

As shown in Table 5, the ANOVA result illustrated that there was a significant relationship between teacher support and WTC in English ( $F=42.047, \rho=.000)$ at the significance level of $\mathrm{p}<.05$.
Table 5. Stepwise Multiple Regression Analysis: ANOVA

\begin{tabular}{cccccc}
\hline & $\begin{array}{c}\text { Sum of } \\
\text { Squares }\end{array}$ & df & $\begin{array}{c}\text { Mean } \\
\text { Square }\end{array}$ & $F$ & Sig. \\
\hline Regression & 32.400 & 1 & 32.400 & $\begin{array}{c}42.0 \\
47\end{array}$ & .000 \\
\hline Residual & 97.092 & 126 & .771 & & \\
\hline Total & 129.492 & 127 & & & \\
\hline
\end{tabular}

Note: ANOVA= Analysis of Variance

\section{Research Question 5:}

Do the data gathered fit with the hypothesized model of WTC in English and classroom environment in normal universities in Shandong Province, China?

As per Byrne (2016), the crucial goal of the model-testing technique was to verify the goodness-of-fit between the data for the research sample and the proposed model. The results obtained by the SEM technique were shown in Figure 2.

As per the structural model presented in Figure 2, it was indicated that all the fitness indexes have achieved with an acceptable level. This illustrated that the goodness-of-fit between this structural model with the data gathered from Shandong normal universities in China. The standardized $\beta$ value for classroom environment $\rightarrow$ WTC in English is .59, denoting that when classroom environment increases by 1 standard deviation, WTC in English would accordingly increase by .59 standard deviation. The multiple correlation $\mathrm{R}^{2}$ coefficients for classroom environment and WTC in English is .35, which demonstrated that classroom 
environment could predicate $35 \%$ of the variance in WTC in English. This interpreted that there were as many as 65\% of the variance in WTC in English were unable to be predicted by classroom environment as this may be brought about by other factors (variables) not studied in this research.

\section{Discussion}

The analysis output of the Person product-moment correlation test illustrated that there was a statistically significant positive relationship that was moderately strong between classroom environment and WTC in English. The positive relation implied that students who perceived a higher level of classroom environment would present a higher level of WTC in English. Thereby, classroom environment was proved as one of the facilitative factors influencing WTC in English. This was buttressed by the empirical research results achieved by Peng (2019), Cao (2014), Khajavy et al. (2018), Khajavy et al. (2016) and Joe et al. (2017), who stated that as a contextual antecedent of L2 WTC in English, classroom environment comprised of group size, topic, interlocutor, task, and teacher places an important role on the enhancement of WTC in English.

Furthermore, as mentioned above, this study not only explored classroom environment from the perspective of the ecological paradigm but also the perspective of PosPsy. Thus, the correlation relationship between classroom environment and WTC in English confirmed in this study is also consistent with the essential concepts highlighted by the Positive Psychology Perspective on SLA (PosPsySLA), namely, positive factors, such as positive institutions (i.e. positive classrooms) exert facilitative influence towards the success of foreign language teaching and the happiness of foreign language teachers and students (Li \& Jiang, 2017).

Additionally, according to the multiple regression analysis results, it was reported that teacher support dimension underlying classroom environment was a statistically significant predictor of L2 WTC in English for the research sample. This finding indicated that students' level of WTC in English would be boosted when teachers were embedded with trust, interest, friendliness, and help toward students. This finding was aligned with $\mathrm{Yu}$ (2015), Kang (2005), and Cao (2014).

The SEM analysis employing AMOS indicated that the hypothesized model involving classroom environment and WTC in English achieved all the required fitness indexes at an acceptable level. This meant that the hypothesized structural model fits well with the data gathered from normal universities of Shandong Province of China. Hence, the hypothesized model was considered to be verified and established in the sample.

\section{Conclusion}

In this study, drawing an incorporated theoretical perspective including ecological paradigm and positive psychology, we aimed to investigate the relationship between classroom environment and L2 WTC in English and incorporated them into a structural model using SEM with AMOS 23.0.

In China, College English course is one of the compulsory subjects for all the sophomores and freshmen. According to the Ministry of Education of China, to cultivate the communicative competence of Chinese EFL students and enable them to proficiently communicate in English in their work, social communication, and learning is considered as one of the most important goals for TEFL in China (College English Curriculum Requirements, 2007)

The positive correlation between classroom environment and WTC in English implied that regular professional development to establish a positive environment would contribute to increasing the level of WTC in English. Thus, to enhance the level of WTC in English, teachers need to provide a relaxed and friendly atmosphere or environment to facilitate suitable interaction with the students.

Moreover, giving an instant positive feedback to the learners (Pishghadam \& Khajavy, 2014), offering postponed error correction (Zarrinabadi, 2014), behaving in friendly and helpful (Kang, 2005; Zarrinabadi, 2014), and selecting familiar and attractive topics for dialogue (Cao, 2014; Peng, 2019) are amid the measures that Chinese language teachers could employ to increase EFL learners' WTC. Last but not least, this study provides evidence research for exploring positive institutions into SLA research and thereby responding to the call for these attempts proposed by Li and Jiang (2017).

\section{REFERENCES}

[1] Bronfenbrenner, U. (1979). The ecology of human development. Cambridge, MA: Harvard university press.

[2] Byrne, B. M. (2016). Structural Equation Modeling With AMOS: Basic Concepts, Applications, and Programming (3rd edition). New York: Taylor \& Francis Group.

[3] Cao, Y. (2011). Investigating situational willingness to communicate within second language classrooms from an ecological perspective. System, 39(4), 468-479. doi:10.1016/j.system.2011.10.016

[4] Cao, Y. (2014). A sociocognitive perspective on second language classroom willingness to communicate. TESOL Quarterly, 48(4), 789-814. doi:10.1002/tesq.155

[5] Cetinkaya, Y. B. (2005). Turkish college students' willingness to communicate in English as a foreign language. 
(Electronic Thesis or Dissertation), Columbus, OH: Ohio State University.

[6] Chua, Y. P. (2013). Mastering Research Statistics. Malaysia: McGraw-Hill Education.

[7] Clément, R., Baker, S. C., \& MacIntyre, P. D. (2003). Willingness to communicate in a second language: The effects of context, norms, and vitality. Journal of Language and Social Psychology, 22(2), 190-209. doi:10.1177/0261927X03022002003

[8] Clément, R., Dörnyei, Z., \& Noels, K. A. (1994). Motivation, self-confidence, and group cohesion in the foreign language classroom. Language Learning, 44(3), 417-448. doi:10.1111/j.1467-1770.1994.tb01113.x

[9] Cohen, J. (1988). Statistical Power Analysis for the Bahavioral Sciences (Second ed.). Hillsdale, New Jersey: Lawrence Erlbaum Associates, Inc.

[10] College English Curriculum Requirements. (2007). Retrieved from http://www.moe.gov.cn/publicfiles/business/htmlfiles/moe/ cmsmedia/image//UserFiles/File/2008/05/06/2008050611/2 008050611_163068.doc.

[11] Creswell, J., \& Guetterman, T. (2019). Educational research: Planning, conducting, and evaluating quantitative and qualitative research (6th Edition ed.). New York, US: Pearson.

[12] Dewaele, \& Li, C. (2020). Emotions in Second Language Acquisition: A critical review and research agenda. Foreign Language World, 196(1), 34-49.

[13] Dorman, J. P. (2003). Cross-national validation of the What Is Happening In this Class?(WIHIC) questionnaire using confirmatory factor analysis. Learning Environments Research, 6(3), 231-245. doi:10.1023/A:1027355123577

[14] Fraenkel, J. R., Wallen, N. E., \& Hyun, H. H. (2011). How to design and evaluate research in education: New York: McGraw-Hill.

[15] Fraser, Fisher, D. L., \& McRobbie, C. J. (1996). Development, validation and use of personal and class forms of a new classroom environment instrument. Paper presented at the Annual meeting of the American educational research association, New York.

[16] Fraser, Treagust, D. F., \& Dennis, N. C. (1986). Development of an instrument for assessing classroom psychosocial environment at universities and colleges. Studies in Higher Education, 11(1), 43-54. doi:10.1080/03075078612331378451

[17] Ghonsooly, B., Khajavy, G. H., \& Asadpour, S. (2012). Willingness to communicate in English among Iranian nonEnglish major university students. Journal of Language and Social Psychology, 31, 197-211. doi:10.1177/0261927X12438538

[18] Joe, H.-K., Hiver, P., \& Al-Hoorie, A. H. (2017). Classroom social climate, self-determined motivation, willingness to communicate, and achievement: A study of structural relationships in instructed second language settings. Learning and Individual Differences, 53, 133-144. doi:10.1016/j.lindif.2016.11.005

[19] Kang, S.-J. (2005). Dynamic emergence of situational willingness to communicate in a second language. System, 33(2), 277-292. doi:10.1016/j.system.2004.10.004

[20] Khajavy, G. H., Ghonsooly, B., Hosseini Fatemi, A., \& Choi, C. W. (2016). Willingness to communicate in English: A microsystem model in the Iranian EFL classroom context. TESOL Quarterly, 50(1), 154-180. doi:10.1002/tesq.204

[21] Khajavy, G. H., MacIntyre, P. D., \& Barabadi, E. (2018). Role of the emotions and classroom environment in willingness to communicate: Applying doubly latent multilevel analysis in second language acquisition research. Studies in Second Language Acquisition, 40(3), 605-624. doi:10.1017/s0272263117000304

[22] Lake, J. (2013). Positive L2 self: Linking positive psychology with L2 motivation. In M. T. Apple, D. D. Silva, \& T. Fellner (Eds.), Language learning motivation in Japan (pp. 225-244). Bristol: Channel View Publications.

[23] Leather, J., \& Dam, J. V. (2003). Towards an ecology of language acquisition. In J. Leather \& J. van Dam (Eds.), Ecology of Language Acquisition (pp. 1-29). Dordrecht: Springer Netherlands.

[24] Li, C., \& Jiang, G. (2017). Positive psychology perspectives on foreign language learning and teaching. International Journal of Bilingual Education and Bilingualism, 1-3. doi:10.1080/13670050.2017.1350279

[25] Liu, J. (2002). Negotiating silence in American classrooms: Three Chinese cases. Language and Intercultural Communication, 2(1), 37-54. doi:10.1080/14708470208668 074

[26] Long, M. H. (1996). The role of the linguistic environment in second language acquisition. In W. C. Ritchie \& T. K. Bahtia (Eds.), Handbook of Second Language Acquisition (pp. 412-468). New York, NY: Academic Press.

[27] MacIntyre, \& Charos, C. (1996). Personality, attitudes, and affect as predictors of second language communication. Journal of Language and Social Psychology, 15(1), 3-26. doi:10.1177/0261927x960151001

[28] MacIntyre, Dörnyei, Z., Clément, R., \& Noels, K. A. (1998). Conceptualizing willingness to communicate in a L2: A situational model of L2 confidence and affiliation. The Modern Language Journal, 82(4), 545-562. doi:10.1111/j.1540-4781.1998.tb05543.x

[29] MacIntyre, \& Mercer, S. (2014). Introducing positive psychology to SLA. Studies in Second Language Learning and Teaching, 2, 153-172. doi:10.14746/ssllt.2014.4.2.2

[30] MacIntyre, P. D. (2007). Willingness to communicate in the second language: Understanding the decision to speak as a volitional process. The Modern Language Journal, 91(4), 564-576. doi:10.1111/j.1540-4781.2007.00623.x

[31] Maslow. (1954). Motivation and personality. New York: Harper \& Row.

[32] Oxford, R., \& Shearin, J. (1994). Language Learning Motivation: Expanding The Theoretical Framework. The Modern Language Journal, 75(1), 12-28. doi:10.1111/j.1540-4781.1994.tb02011.x

[33] Pawlak, M., Mystkowska-Wiertelak, A., \& Bielak, J. (2016). Investigating the nature of classroom willingness to communicate (WTC): A micro-perspective. Language 


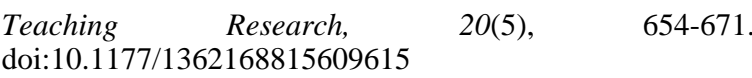

[34] Peng, J.-E. (2012). Towards an ecological understanding of willingness to communicate in EFL classrooms in China. System, 40(2), 203-213. doi:10.1016/j.system.2012.02.002

[35] Peng, J.-E. (2019). The roles of multimodal pedagogic effects and classroom environment in willingness to communicate in English. System, 82, 161-173. doi:10.1016/j.system.2019.04.006

[36] Peng, J.-E., \& Woodrow, L. (2010). Willingness to communicate in English: A model in the Chinese EFL classroom context. Language Learning, 60(4), 834-876. doi:10.1111/j.1467-9922.2010.00576.x

[37] Pishghadam, R., \& Khajavy, G. H. (2014). Development and validation of the Student Stroke Scale and examining its relation with academic motivation. Studies In Educational Evaluation, 43, 109-114. doi:10.1016/j.stueduc.2014.03.00 4

[38] Seligman, M. E. P., \& Csikszentmihalyi, M. (2000). Positive psychology: An introduction. American Psychologist, 55(1), 5-14. doi:10.1037/0003-066x.55.1.5

[39] Swain, M., \& Lapkin, S. (1995). Problems in output and the cognitive processes they generate: A step towards second language learning. Applied Linguistics, 16, 371-391. doi:10.1093/applin/16.3.371

[40] Tabachnick, B. G., \& Fidell, L. S. (2019). Using Multivariate Statistics (7th Edition ed.). Boston, MA: Pearson Education Inc.
[41] Weaver, C. (2005). Using the Rasch model to develop a measure of second language learners' willingness to communicate within a language classroom. Journal of applied measurement, 6(4), 396-415.

[42] Wei, H., Gao, K., \& Wang, W. (2019). Understanding the relationship between grit and foreign language performance among middle school students: The roles of foreign language enjoyment and classroom environment. Frontiers in Psychology, 10(1508). doi:10.3389/fpsyg.2019.01508

[43] You, C., \& Dörnyei, Z. (2014). Language learning motivation in China: Results of a large-scale stratified survey. Applied Linguistics, 37(4), 495-519. doi:10.1093/applin/amu046

[44] Yu. (2001). Communicative Language Teaching in China: Progress and Resistance. TESOL Quarterly, 35(1), 194-198. doi: $10.2307 / 3587868$

[45] Yu. (2015). An examination of the dynamic feature of WTC through dyadic group interaction. System, 55, 11-20. doi:10.1016/j.system.2015.08.001

[46] Zarrinabadi, N. (2014). Communicating in a second language: Investigating the effect of teacher on learners' willingness to communicate. System, 42, 288-295. doi:10.1016/j.system.2013.12.014

[47] Zhang, Q., \& Oetzel, J. G. (2006). Constructing and validating a teacher immediacy scale: A Chinese perspective. Communication Education, 55(2), 218-241. doi:10.1080/03634520600566231 